INNOVACIÓN

\title{
Dinâmicas de grupo aplicadas aos alunos do curso de Direito
}

\author{
Group dynamics applied to Law students \\ Natalia M. M. Prigol \\ Universidade Católica de Paraná, Brasil \\ Thiago Werner Ramasco \\ Universidade Católica de Paraná, Brasil
}

\begin{abstract}
RESUMO Objetiva-se com o trabalho demonstrar como é possível utilizar dinâmicas de grupo para os estudantes de Direito, e o quão positivo isto pode ser ao professor e aos alunos. Para tanto, partir-se-á da análise do conceito de «dinâmica de grupo» e quais seus requisitos para que sejam bem-sucedidas. Após, serão expostas algumas dinâmicas de grupo que são frequentemente utilizadas pelos professores, demonstrando qual o objetivo de cada uma delas. Por fim, intenta-se demonstrar, a partir de exemplos, como as dinâmicas podem ser aplicadas aos alunos do curso de Direito, no intuito de rechaçar a ideia de que referido curso impossibilita que os professores se valham de tal técnica, por ser demasiadamente teórico.
\end{abstract}

PALAVRAS-CHAVE Dinâmicas de grupo; Direito; Ensino Pedagógico.

ABSTRACT The study aims to demonstrate how it's possible to use group dynamics for law students, and how positive these can be to the professor and to the students. In order to achieve the objective, the study starts with the analysis of the concept of «group dynamics» and what are the requirements necessary to be successful. After that, some group dynamics will be exposed which are often used by professors, demonstrating the purpose of each one of them. Finally, it will be demonstrated, by examples, how the group dynamics can be applied to the law students, in order to reject the idea that law courses make it impossible for professors to use this technique, because it is too theoretical.

KEYWORDS Group dynamic; Law; Teaching. 


\section{Introdução}

Objetiva-se com o presente artigo demonstrar como as dinâmicas de grupo podem ser aplicadas aos alunos do curso de Direito, e como se transformam, se bem utilizadas, em instrumentos valiosos aos professores do ramo.

Em que pese ser um curso eminentemente teórico, a técnica de ensino que se intenta analisar pode e deve ser aplicada, no intuito de demonstrar a dinamicidade da prática jurídica.

O artigo foi dividido em três capítulos. No primeiro, objetivou-se analisar como se dá uma dinâmica de grupo, seus requisitos e qual o objetivo com referida técnica. No segundo capítulo, tratou-se de analisar algumas técnicas de dinâmica de grupo utilizadas.

Por fim, no terceiro capítulo, objeto do presente trabalho, foram expostas as possibilidades de aplicação de dinâmicas de grupo aos estudantes do curso de Direito, com a esperança de encorajar os professores do ramo a aplicarem as técnicas aos seus alunos.

Justifica-se a elaboração da pesquisa para incentivar os professores de cursos jurídicos à aplicarem novas técnicas de ensino que, a longo prazo, trazem um resultado mais positivo aos alunos e reduzem as falhas no rendimento da aprendizagem. (Pérez-Perdomo, 2018; Carvalho, 2017; Prado Carrera, 2016; Pinilla-Rodríguez et al, 2017; Montoya, 2010; Lobo, 2017; González, 2013; Fernández-Figares, 2015; González, 2012; Elgueta, Palma, 2014; Diez et al, 2014; Clavijo, 2015; Gómez, Menares, 2014)

Utilizou-se do método dedutivo, porque o estudo parte do geral (dinâmicas de grupo aplicadas a todos os alunos) para o particular (dinâmicas de grupo voltadas para os estudantes de Direito).

\section{Técnica de ensino: Dinâmicas de grupo}

O objetivo deste capítulo é analisar a técnica de ensino de dinâmica de grupo. Para tanto, será exposto como se forma um grupo dentro da sala de aula, e qual o intuito com a utilização da referida técnica. (Zárate-Rueda, 2017; Rodríguez et al, 2017; Palomino, 2016; Palazón-Pérez, 2011; Leris et al, 2017; Casado, Rebolledo, 2017; Arnáiz, Bernardino, 2012; Andreu-Andrés, 2016).

Kurt Lewin foi um dos primeiros teóricos a estudar os grupos, analisar os seus comportamentos e as suas formas de relacionamento, cujo fenômeno ele denominou de «Dinâmica dos Grupos», primeiramente em 1944, em um artigo publicado pelo autor (Cuzin, 2008). Ele foi responsável por criar uma teoria - Teoria de Campo - a partir da qual concluiu que os indivíduos se comportam «de acordo com suas percepções, ou seja, reage conforme aquilo que é confortável ou não com suas cognições» (Wanderley, 2016). 
Além dele, destaca-se as contribuições de Wilfred Ruprecht Bion acerca das dinâmicas, o qual defendia que os grupos eram um campo de diversas descobertas que devem ser realizadas através da interpretação. Para ele, «o fato de que o grupo se constitua em um lugar determinado e em um momento determinado é importante [..] mas não tem maior significado para a produção de fenômenos de grupo; a ideia de que isso seja significativo surge da impressão que estabelece que uma coisa começa no memento em que sua existência se torna palpável» (Bion, 1975).

No Brasil, o tema foi primeiramente abordado por Pierre Weil, no Departamento de Orientação e Treinamento do Banco da Lavoura de Minas Gerais, e na Universidade Federal de Minas Gerais (Weil, 1967). Para o autor, o principal objetivo com as dinâmicas de grupo era «identificar e tratar os obstáculos à comunicação e às causas do conflito» (Weil,1997).

Dorwin Cartwright e Alvin Zander (1967) conceituam as dinâmicas de grupo da seguinte forma:

A dinâmica de grupo é o estudo das forças que agem no seio dos grupos, suas origens, consequências e condições modificadoras do comportamento do grupo. Sua importância para a organização é a de que, considerando os grupos responsáveis pelos atingimentos dos objetivos organizacionais, a variação no comportamento do grupo é de conhecimento vital para o administrador. A formação do grupo fundamenta-se na ideia de consenso nas relações interpessoais, ou seja, concordância comum sobre os objetivos e sobre os meios de alcança-los, resultando a solidariedade grupal.

Para fins de dinâmica, é preciso, primeiramente, que se tenha um «grupo», que é um «conjunto restrito de pessoas, que, ligadas por constantes do tempo e espaço e articuladas por sua mútua representação interna, propõe-se, explícita ou implicitamente, a uma tarefa, que constitui sua finalidade» (Vera, 2007). Noutras palavras, é preciso que os sujeitos estejam vinculados e interajam em busca de um objetivo comum, notadamente o caso de uma sala de aula onde os alunos estão vinculados e objetivam a formação acadêmica.

A formação de grupos dentro da sala de aula tem como escopo o ensino-aprendizagem, que objetiva demonstrar ao aluno como «aprender a aprender». Trata-se, em breves palavras, de um processo de interação e comunicação entre os participantes do grupo (Cunha et al, s/f), comumente chamada de dinâmica de grupo.

A dinâmica de grupo é um instrumento educacional valioso «que pode ser utilizado para trabalhar o ensino-aprendizagem quando opta-se por uma concepção de educação que valoriza tanto a teoria quanto a prática e considera todos os envolvidos neste processo como sujeitos» (Perpétuo, 2005).

Atualmente, rejeita-se a concepção de que ao aluno cabe apenas o papel de memorizar conteúdos. A transformação nos conceitos de ensino e aprendizagem de- 
monstram que o aluno deve pensar e desenvolver seu intelecto não só através da exposição de conteúdos, mas, principalmente, através de experiências proporcionadas dentro da sala de aula, que comprovadamente auxiliam o processo de aprendizagem (Lessa, 2014).

A opção por uma dinâmica de grupo como uma técnica de ensino impõe ao professor um extenso planejamento para que o objetivo com a dinâmica seja alcançando (Alberti et al, 2014). Ao optar pela realização de uma dinâmica de grupo, deve observar os seguintes pontos: (i) objetivo, (ii) ambiente, (iii) duração, (iv) número de participantes, (v) materiais, (vi) perguntas e conclusões.

Em apertada síntese, o professor deve ter em mente com exatidão qual o objetivo que pretende atingir com a realização da pesquisa (i), se o espaço onde ele intenta desenvolver a dinâmica comporta a atividade (ii), se o tempo disponível é suficiente, (iii), se o número de pessoas é adequado (iv), se os recursos que estão disponíveis bastam (v) e, a conclusão que será extraída ao final da dinâmica de modo a sintetizar a atividade (vi) (Amaral, 2007:13).

Para que a dinâmica seja exitosa é necessário que o professor observe todos os pontos acima, evitando-se a realização de atividades que não contribuem para o crescimento acadêmico do aluno ou que não atinjam o objetivo almejado.

Além disto, as dinâmicas devem conter três componentes: (i) sua aplicação como método de eleição em situações de aprendizagem; (ii) a reprodução de uma situação a ser experimentada pelo grupo; (iii) a presença de um elemento conectado à atividade da dinâmica (Silva, 2008:85). Independentemente do grau de criatividade do professor que está aplicando a dinâmica, estes três elementos estão diretamente vinculados ao caráter educacional da atividade.

A importância desses métodos de aprendizagem socializantes é destacada por Lívia Dias Coelho, a qual afirma que eles «(...) oferecem aos alunos, em conjunto, oportunidades de cooperação e solução de problemas, favorecendo intenso dinamismo interpessoal» (Coelho, 2013:101).

A autora ressalta também a importância do papel desempenhado pelo professor nesses métodos de aprendizagem, que não pode se limitar a observar o desenvolvimento das atividades, mas, ao contrário, deve ter participação efetiva tanto na formação dos grupos quanto no transcorrer da aula:

O professor é o responsável, em sala de aula, pelo controle das tendências à formação de grupos definidos ('panelas'), muitas vezes totalmente divorciados do conjunto da classe. Também os alunos devem conhecer as razões da diversificação de grupos, permitindo-se experimentar novos contatos sociais e novos 'encaixes' intelectuais, coletando experiências e desenvolvendo, progressivamente, seu ajustamento com os colegas. (Coelho, 2013:101)

Lívia Dias Coelho elenca os seguintes métodos de ensino socializante: debate, 
demonstração, dialética, diálogos sucessivos, discussão circular, discussão em pequenos grupos, grupo na berlinda, G.V.G.O., júri pedagógico, júri simulado, painel integrado, Phillips 66, seminário e tempestade cerebral. (Coelho, 2013: 116-172)

Obviamente, não é a intenção do presente estudo esmiuçar cada uma dessas técnicas, mormente porque a classificação varia conforme o autor; mas, sim, apresentar algumas que poderiam ser empregadas pelos professores nas salas de aulas dos cursos de Direito, pois colaboram para a formação da capacidade argumentativa dos alunos, habilidade imprescindível para o profissional do Direito, em qualquer dos campos de atuação que venha a escolher.

A relevância deste método também é destacada por Cleber Tiago Cirineu, Regina Célia Fiorati e Francine Baltazar Assad, que defendem que o trabalho em grupo «permite que haja uma interação mútua entre as pessoas envolvidas, oferecendo assim, novas descobertas e novos conhecimentos a partir de uma construção coletiva que possibilita um novo olhar sobre a percepção de si e do outro» (Cirineu, 2016:350).

Como se nota, a importância da força pedagógica do grupo é destacada como uma fonte de socialização moral e política do indivíduo (Dalbosco, 2015), sendo um instrumento importante no processo de desenvolvimento do ensino.

\section{Técnicas de dinâmica de grupo}

Objetiva-se neste capítulo, sem pretensão de exaurir a matéria, expor algumas técnicas de dinâmica de grupo que auxiliam os professores e alunos na exposição e compreensão do conteúdo.

\section{Técnica de dinâmica de grupo «quebra gelo»}

O objetivo deste gênero de dinâmica é garantir uma primeira abordagem a um determinado assunto, diminuindo as barreiras entre as pessoas (alunos) e o dinamizador (professor), haja vista ser natural uma fase de inibição inicial (Rui Tinoco, 2014).

Exemplificando-se, uma atividade «quebra gelo» é aquela onde o professor orienta os alunos a andarem pela sala de aula de forma aleatória e, após certo tempo, solicita que eles se agrupem de acordo com algum elemento em comum, por exemplo, cores preferidas (Rui Tinoco, 2014:11).

Isto possibilita que os alunos se comuniquem com os demais da classe e encontrem interesses em comum, iniciando uma sociabilização em sala de aula.

Neste tipo de atividade é fundamental oportunizar e estimular os alunos a trocarem informações e incluir todos os alunos na atividade, de tal forma que todos façam parte do mesmo grupo. São exemplos de atividades «quebra-gelo» o nó humano, o urso, as cadeiras, dentre outros (Universidade Luterana do Brasil).

Após este período inicial, cabe ao professor ultrapassar a etapa de quebra gelo 
e iniciar, através de uma nova instrução, a abordagem de temas mais específicos, já com a classe mais descontraída.

\section{Técnica de dinâmica de grupo «campo minado»}

Outra técnica de dinâmica de grupo bastante utilizada é a denominada «campo minado». Referida dinâmica se dá da seguinte forma: em um retângulo desenhado no chão da sala de aula, com diversas divisórias, são distribuídos objetos em cada uma das divisórias e, algumas destas divisórias são denominadas «campo minado».

Os alunos, em duplas, devem realizar a travessia de um lado para o outro do retângulo, com os olhos vendados, sem poder tocar nos objetos e sem passar por qualquer divisória classificada como «campo minado».

A travessia deve ser realizada por um integrante da dupla, que estará com os olhos vedados, enquanto o outro tem o papel de guiá-lo no intuito de desviar dos «campos minados» e finalizar a travessia.

Esta técnica tem como «objetivo levar os alunos a refletirem sobre a importância de a comunicação docente ser clara, pensada e adequada às necessidades e aos entendimentos do público ouvinte» (Scheibel, s/f).

\section{Técnica «grupo na berlinda»}

Esse método é bastante utilizado por não demandar uma preparação prévia dos participantes. Trata-se de submeter as ideias de um subgrupo, na sala de aula, à crítica dos demais estudantes, abordando os diversos pontos de vista sobre um assunto polêmico.

Esta técnica tem como objetivo «desenvolver o raciocínio, o pensamento lógico, a linguagem oral, os valores éticos (crítica, solidariedade e companheirismo)» (Nunes, 2003: 187), incentivando os alunos a «argumentar contra ou a favor de determinado tema referente ao conteúdo de disciplina»( Nunes, 2003: 187).

O professor deve dividir a classe em grupos de aproximadamente cinco participantes cada e distribuir um texto que trate sobre uma matéria polêmica. Em seguida, cada um dos grupos deverá designar, dentre seus participantes, um relator. O grupo, então, analisa o texto fornecido pelo professor e, após estudar o assunto, passa a levantar argumentos em defesa de um determinado ponto de vista que esteja relacionado à matéria.

O relator deve anotar atentamente todos os argumentos expostos por seus colegas de grupo, sendo permitido ao professor auxiliar os grupos com a argumentação e até mesmo sugerir temas que gerem intenso debate.

$\mathrm{Na}$ sequência, os relatores de cada um dos grupos devem se posicionar em frente aos demais participantes - em uma espécie de semicírculo (Almeida, 2003:187) - e 
ler, cada qual, o relatório de seu respectivo subgrupo. Feita essa leitura, os demais participantes irão escolher qual dos temas quer debater.

Escolhido o tema do debate, todo o subgrupo do relator eleito irá para a berlinda, em local de destaque diante de toda a classe, oportunidade em que é realizada uma releitura do relatório para suscitar na classe o aparecimento de opiniões divergentes.

Aqueles alunos da classe que tiverem interesse em confrontar a opinião do grupo na berlinda devem se manifestar erguendo a mão. Caso haja intensa participação, recomenda-se o estabelecimento de uma lista de inscrição, cuja ordem será observada no debate.

Não há diálogo entre os debatedores, mas sim réplicas e tréplicas.

Qualquer um dos integrantes do grupo na berlinda pode atuar em defesa das ideias do grupo, não apenas o relator. Essa necessidade de defender o ponto de vista comum cria coesão entre os membros do grupo na berlinda e uma conotação de competição positiva para o início de um estudo.

\section{Técnica «discussão circular»}

É uma exposição de ideias acerca de um determinado assunto, sem que haja divergência ou disputa entre os envolvidos.

Essa técnica é ideal para grupos menores, que ficarão dispostos em círculo na sala de aula. Cada um dos integrantes dispõe de um minuto para falar. Um coordenador, que pode ser o professor, irá dirigir os trabalhos; e um redator irá anotar as ideias expostas pelos demais integrantes da discussão, lendo-as ao final da atividade.

O coordenador inicia a discussão expondo o tema e, em seguida, passa a palavra para o participante à sua direita. Esse fará a discussão e, esgotado seu tempo, a palavra passa para o seguinte e assim sucessivamente até fechar o círculo. Nessa primeira rodada todos devem falar. Nas rodadas seguintes, aqueles que não quiserem se manifestar poderão ceder seu tempo aos interessados. A atividade continua enquanto houver riqueza de ideias nas exposições ou conforme o tempo permitir.

Lívia Dias Coelho afirma que o «(...) tempo de um minuto para cada colocação pode gerar conflito pessoal, porém a manutenção dessa norma é questão fundamental para o exercício de síntese das ideias»( Dias, 2013:133)

Desta forma, cabe ao professor organizar e gerir esta técnica, para assegurar o êxito da atividade.

\section{Dinâmicas de grupo aplicadas aos estudantes de Direito}

No curso de Direito, as aulas são em grande parte meramente expositivas, extensas e cansativas, o que causa arrepios em muitos além de prejudicar o processo de aprendizagem. Isto se dá, principalmente, porque a maioria dos professores se limi- 
tam à exegese do Direito, apresentando um sistema pronto, acabado, e supostamente harmônico passível de responder todas as perguntas jurídicas existentes (Carvalho, 2016:6), o que não é verdade.

É preciso incitar os alunos a realizarem perguntas, a se questionarem sobre aquilo que está sendo exposto pelos professores, evitando um distanciamento entre a teoria e a realidade (Faría, 1995:28).

Evidente que se de uma tarefa árdua, ainda mais se se considerar a proliferação de cursos de Direitos nos últimos anos, no entanto, conforme assevera Sérgio Rodrigo Martinez acerca de tal proliferação, «em relação aos cursos já existentes, estes devem se aprimorar cada vez mais a fim de ocuparem lugar de destaque no cenário jurídico e educacional brasileiro» (Martínez, 2005:22).

Neste intuito, a Resolução CNE/CES n ${ }^{\circ}$, de 29 de setembro de 2004, aprovou a Diretriz Nacional Curricular do curso de Direito. O artigo $2^{\circ}$ dessa norma dispõe:

Art. $2^{\circ}$ A organização do Curso de Graduação em Direito, observadas as Diretrizes Curriculares Nacionais se expressa através do seu projeto pedagógico, abrangendo o perfil do formando, as competências e habilidades, os conteúdos curriculares, o estágio curricular supervisionado, as atividades complementares, o sistema de avaliação, o trabalho de curso como componente curricular obrigatório do curso, o regime acadêmico de oferta, a duração do curso, sem prejuízo de outros aspectos que tornem consistente o referido projeto pedagógico.

$\$ 1^{\circ}$ O Projeto Pedagógico do curso, além da clara concepção do curso de Direito, com suas peculiaridades, seu currículo pleno e sua operacionalização, abrangerá, sem prejuízo de outros, os seguintes elementos estruturais:

I - concepção e objetivos gerais do curso, contextualizados em relação às suas inserções institucional, política, geográfica e social;

II - condições objetivas de oferta e a vocação do curso;

III - cargas horárias das atividades didáticas e da integralização do curso;

IV - formas de realização da interdisciplinaridade;

V - modos de integração entre teoria e prática;

VI - formas de avaliação do ensino e da aprendizagem;

VII - modos da integração entre graduação e pós-graduação, quando houver;

VIII - incentivo à pesquisa e à extensão, como necessário prolongamento da atividade de ensino e como instrumento para a iniciação científica;

IX - concepção e composição das atividades de estágio curricular supervisionado, suas diferentes formas e condições de realização, bem como a forma de implantação e a estrutura do Núcleo de Prática Jurídica;

$\mathrm{X}$ - concepção e composição das atividades complementares; e,

XI - inclusão obrigatória do Trabalho de Curso .(Ministério Educação, Brasil)

Apesar da referência expressa às formas de realização da interdisciplinaridade e aos modos de integração entre teoria e prática, a falta de sensibilidade dos profes- 
sores da área no que concerne a necessidade do aluno vivenciar na prática o que o professor tenta, a todo custo, ensinar apenas na teoria, é um dos fatores a ser levado em consideração quando se analisa o número de alunos que desistem do curso e a necessidade de outros de iniciar logo em seguida uma pós-graduação.

Em que pese o Direito ser, de fato, demasiadamente teórico, isto não impede que o professor se valha de técnicas de ensino que possam auxiliar os alunos em uma maior compreensão da matéria e absorção do conteúdo. Faz-se necessário «pensar o ensino do direito a partir de outros paradigmas teóricos e metodológicos» (Duro, Machado, 2014:27) sendo um exemplo disto a técnica de ensino protagonista da pesquisa.

Objetiva-se rechaçar neste capítulo a concepção de não ser possível promover dinâmicas de grupo para alunos do curso de Direito, por se tratar de uma matéria eminentemente teórica.

Um primeiro exemplo de dinâmica de grupo que pode ser utilizada pelos professores é a simulação de uma audiência dentro da sala de aula. Explica-se: um professor responsável por disciplinar uma matéria de direito processual, ao lecionar aos alunos como funciona uma audiência, ao invés de simplesmente expor as normas que regem o ato solene, efetivamente simular a sua realização, através de uma dinâmica de grupo, logrará muito mais êxito na transmissão de conhecimento do que um professor que se limitou a repassar aos alunos as normas que devem seguir.

O instrumento da dinâmica, neste caso, demonstrará a dinamicidade do ato e as possibilidades que podem derivar em razão de manifestações das partes.

Se a cada aluno da classe onde se intenta fazer a dinâmica tiver um papel específico na «audiência», cujas tarefas devem inclusive serem distribuídas com pelo menos uma aula de antecedência, o objetivo final do professor muito provavelmente será atingido de maneira mais eficiente do que acaso se limitasse a transmitir aos alunos as normas para realização do ato.

Evidentemente que tal dinâmica deve levar em consideração toda a logística que a técnica demanda, tais como: espaço, tempo, número de alunos, recursos necessários, etc., conforme exposto no capítulo primeiro.

De toda sorte, devidamente observados tais critérios, necessários para assegurar o bom desenvolvimento da dinâmica, certamente o professor logrará êxito em lecionar de forma muito mais eficiente o ato da audiência.

O segundo exemplo que se intenta expor é o do júri simulado.

Conquanto seja comum nas faculdades de Direito a realização de júris simulados, percebe-se que está limitado a eventos esporádicos, em geral organizados pelos centros acadêmicos e com participação dos alunos exclusiva àqueles que se interessarem pela atividade.

O ideal seria que tais técnicas fizessem parte do dia a dia do estudante de Direito em várias matérias, estimulando-se a participação de todos os alunos em sala de aula.

Verifica-se que os cursos preparatórios para o ingresso nas carreiras jurídicas de- 
dicam mais tempo às práticas socializantes. Nesse passo, citem-se como exemplo as Escolas da Magistratura, que realizam aulas práticas com júris e audiências simuladas, as quais integram a grade curricular do curso.

Em sua dissertação de mestrado sobre a situação de aprendizagem escolar em grupo e suas implicações no desenvolvimento individual, Solange Rauchback Garani realizou um estudo detalhado sobre as aulas práticas ministradas na EMAP - Escola da Magistratura do Paraná. Para a autora:

(...) o contexto social em que o adulto está inserido repercute no desenvolvimento e na aprendizagem, pois podem facilitar ou impedir o progresso individual. Nessa perspectiva, as interações sociais ganham espaço no âmbito escolar, porque valorizam o compartilhar de experiências, condição fundamental para a aprendizagem do adulto. (Garani, 2004:50)

A conclusão da pesquisa aponta que os resultados das metodologias práticas implementadas na EMAP «(...) foram significativos para a formação do futuro magistrado, mas com aplicações importantes na atividade do advogado e de outros profissionais que lidam com as questões processuais (...)» (Garani, 2004:169). O papel do professor-orientador também foi frisado na dissertação:

O orientador atento percebe as dificuldades de seus alunos e direciona a aula com base nessa percepção. Conforme os sujeitos pesquisados, os orientadores mais sensíveis buscam identificar as dificuldades individuais de várias formas: a) por meio de perguntas dirigidas ao grupo ou a um dos alunos durante a exposição inicial ou no estudo do caso; b) durante a observação cuidadosa das audiências; c) durante a resolução do trabalho escrito; d) durante a avaliação do trabalho escrito. Assim, em diversas ocasiões o orientador pode identificar eventuais dificuldades e proporcionar a ajuda necessária.(Garani,2004:50)

Ocorre que os cursos preparatórios, tais como a Escola da Magistratura, são abertos aos alunos de Direito a partir do quinto ano apenas. Seria desejável que essas metodologias fossem consideradas como recursos efetivamente eficientes pelos educadores do direito lato senso e, desta forma, aplicadas nas faculdades e universidades que oferecem o curso, dada a sua importância para o desenvolvimento do aprendizado, conforme a conclusão do estudo citado.

O terceiro exemplo que se intenta expor é o uso da tecnologia em grupo.

Existem atualmente diversos mecanismos disponíveis online e de forma gratuita que possibilitam aos alunos que, utilizando seus celulares ou laptop, interajam entre si simultaneamente e de forma positiva.

Tais programas permitem que o professor organize a atividade previamente, formulando perguntas que devem ser respondidas aos alunos quando entrarem no sistema. Cada aluno possuirá uma senha, que é criada em poucos minutos. 
A cada nova pergunta, os participantes vão sendo eliminados à medida que escolhem a resposta errada. Como todos os alunos têm acesso aos resultados, a dinâmica vai criando um ambiente saudável de competição.

Acredita-se que «jogando, o indivíduo se depara com o desejo de vencer que provoca uma sensação agradável, pois as competições e os desafios são situações que mechem com nossos impulsos» (Fialho,2008:298). Neusa Nogueira Fialho ainda afirma que os jogos podem ser um «instrumento facilitador da integração, enfocando a necessidade de alguns cuidados que devem ser tomados ao levarmos um jogo em sala de aula e ressaltando a importância da colocação de regras e pontuações» (Fialho,2008:298).

Portanto, a aplicação de jogos como dinâmicas de grupo é mais um exemplo de como este instrumento pode ser valioso quando aplicado aos estudantes de Direito.

Em suma, intentou-se expor como diferentes técnicas podem ser aplicadas aos alunos de Direito.

\section{Considerações finais}

Foi visto que a Diretriz Nacional Curricular do curso de Direito, atualmente regulada pela Resolução CNE/CES nº 9, de 29 de setembro de 2004, do Ministério da Educação, dispõe de maneira expressa sobre às formas de realização da interdisciplinaridade e os modos de integração entre teoria e prática que precisam ser contemplados no ensino das diversas matérias do curso.

Apesar dessa disposição do MEC, na realidade observa-se que a forma de ministrar as aulas no Direito pouco se alterou nas últimas décadas. A metodologia das aulas expositivas, em que o professor se limita a transferir de maneira unilateral o conhecimento aos alunos, segue uma tendência histórica na cátedra jurídica, que ignora as diversas transformações por que passaram o ensino e a própria sociedade.

O aluno hoje não é o mesmo de anos atrás. Mudou sua forma de pensar e, consequentemente, de aprender. A informação que o professor passa aos alunos em sala de aula pode ser verificada na internet em tempo real, por meio de diversas plataformas. A construção do conhecimento deixa de ser unilateral e passa a ser plurilateral.

Nesse panorama, ganham relevo as formas socializantes de ensino, abordadas no presente artigo. Essas técnicas criam oportunidades de cooperação e solução de problemas entre os alunos, com o dinamismo típico dos dias atuais. Atividades como júris e audiências simuladas e o uso de tecnologias em grupo aliados ao tradicional método expositivo colaboram para conjugar a teoria com a prática, aspecto muitas vezes negligenciado nas universidades brasileiras.

O uso desses instrumentos, porém, requer a participação atenta e efetiva do professor para que seus objetivos sejam atingidos. É preciso respeitar as características dos indivíduos que participarão da atividade, as regras estabelecidas para cada uma 
das formas de dinâmica de grupo e as peculiaridades da matéria ministrada.

Observados esses aspectos, a aula certamente será produtiva e inovadora, criando condições para aprimorar os conhecimentos dos alunos por meio de uma maior interação do grupo. Trata-se de uma reflexão que deve ser feita pelos professores de Direito para que o curso se volte à realidade da sociedade e dos alunos de hoje em dia.

\section{Referências}

Albaerti, Taís Fim; Abegg, Ilse; Costa, Márcia Rejane Julio; Titton, Mauro (2014). «Dinâmicas de grupo orientadas pelas atividades de estudo: desenvolvimento de habilidades e competências na educação professional». Revista Brasileira de Estudos Pedagógicos, Brasília, 95: 346-362.

Almeida, Paulo Nunes de (2003). Educação lúdica: técnicas e jogos pedagógicos (São Paulo: Loyola)

Amaral, Vera Lúcia do (2007). Psicologia da educação: a dinâmica dos grupos e o processo grupal. Natal-RN: EDUFRN.

ANDREU-ANDRÉs, María. Ángeles (2016). «Cooperative or Collaborative Learning: Is There a Difference in University Students' Perceptions?». Revista Complutense de Educación 27(3): 1041-60.

Arnáiz, Cristina Mingorance, and Antonio Calvo Bernardino (2012). «Los resultados de los estudiantes en un proceso de evaluación con metodologías distintas.» Revista de investigación Educativa 31 (1): 275-293.

Bion, Wilfred Ruprecht ((1975). Experiências com grupos: os fundamentos da psicoterapia de grupo, Trad. por Walderedo de Oliveira, Rio de Janeiro: Editora Imago.

Carvalho Veçoso, Fabian (2017). «History and Critique in International Law in Latin America: Revisiting Past Discussions on Legal Education in the Region.» Revista Derecho del Estado, 39: 91-117.

Carvalho, Nathalie de Paula (2016). «Uma análise do ensino jurídico no Brasil.» Revista de Pesquisa e Educação Jurídica, Brasília, 2 (1): 20-39.

Cartwright, Dorwin e Alvin Zander, (1967). Dinâmica de trupo: pesquisa e teoria, Trad. por Dante Moreira Leite e Miriam Moreira Leite. São Paulo: Editora Herder.

Casado, María del Rocío Rodríguez, and Teresa Rebolledo Gámez (2017) «Evaluación de metodologías participativas: una experiencia en el ámbito universitario.» Revista de humanidades (31): 99-122.

Clavijo Cáceres, Darwin (2015) «El enfoque de competencias en la formación del abogado para el siglo XXI.» Justicia (27): 185-212.

Cirineu, Cleber Tiago; Regina Célia Fiorati,; Francine Baltazar Assad, (2016). «A utilização de técnicas de grupo em sala de aula: contribuições para o processo de ensino-aprendizagem na graduação em terapia ocupacional». Revista de Terapia Ocupacional da Universidade de São Paulo. 27 (3): 349-354. 
Cunha, Laura da Silva; Raquel Pinheiro da Silva, Bruno Sérgio Alcântara, (s/f). Um estudo sobre a importância da dinâmica de grupo no processo de aprendizagem de professores. Faculdades Promove de Brasília. Disponível em: <http://nippromove. hospedagemdesites.ws/anais_simposio/arquivos_up/documentos/artigos/354 $\mathrm{d}_{31}$ 34954bf 42coef29a2ea3776de7.pdf.>. Acesso em 26 set. 2017.

Cuzin, Marinalva Imaculada (2008). "As relações interpessoais à luz do psicodrama» (tese de doutorado, Universidade Estadual de Campinas, Faculdade de Educação, http://repositorio.unicamp.br/bitstream/REPOSIP/252067/1/Cuzin_ MarinalvaImaculada_D.pdf

Dalbosco, Claudio Almir (2015). «Formas de reconhecimento e força intersubjetiva de grupo». Revista Educação \& Sociedade, 36 (131) Campinas.

Dias Coelho, Lívia (2013). Procedimento de ensino: um movimento entre a teoria e a prática pedagógica. 2. ed. rev. e ampl. Curitiba: Editora Champagnat PUC-PR.

Duro Dias, Renato e Lúcio Carobin Machado (2014). Desafios e potencialidades para o campo da educação jurídica: um «estado da arte».

Diez Estella, Fernando, and Mercedes de Prada Rodríguez (2014) «Proposals practices in teaching Business Law and Litigation for the acquisition of skills.» Historia y comunicación social (19): 119-132.

Elgueta, María Francisca, and Eric Eduardo Palma (2014). «A Proposed Classification of the Master Class at the Faculty of Law.» Revista Chilena de Derecho 41(3): 907-924.

FARIA, José Eduardo (1995). O ensino jurídico, en Seis temas sobre o ensino jurídico, ed. por João Bosco da Encarnação e Getulino do Espírito Santo Maciel. São Paulo: Cabral.

Fialho, Neusa Nogueira (2008). Os jogos pedagógicos como ferramentas de ensino. Área temática: Educação, Teorias, Metodologias e Práticas. Disponível em: $<$ http://www.pucpr.br/eventos/educere/educere2008/anais/pdf/293_114.pdf.> Acesso em 1 out. 2017.

Fernández-Fígares Morales, María José (2015). «Docencia sobre litigación y oratoria para juicios en los planes universitarios jurídicos.» Opción 31 (2):229-249.

GARANI, Solage Rauchbach (2004). «Interação social na aprendizagem do adulto: estudo de caso das aulas práticas na Escola da Magistratura do Paraná». Dissertação de mestrado, Setor de Educação, Universidade Federal do Paraná, sin editar.

GonzÁLEz Galván, Jorge Alberto (2013). «Legal Education, Research and Intelligents Human Rights.» Boletin Mexicano de Derecho Comparado, 137: 499-527.

-. (2012).»The Pedagogical Constructivism Applied to Law: Towards a Dynamic Formation.» Boletín Mexicano de Derecho Comparado, 133: 119-39.

Gómez Francisco, Taeli and N. Menares Ossandón (2014). «Complex and Constructivist Paradigms Input to the Teaching of Legal Science.» Ius et Praxis 20 (1): 199-220. 
Lerís López, Dolores; Jesús Letosa Fleta; Antonio Usón Sardaña, Pedro Allueva Torres, and Concepción. Bueno García (2017). «Teamwork and Learning Styles in Higher Education.» Revista Complutense de Educación 28 (4): 1267-84.

Lessa, Lidiane Costa; Márcia Moreira Sales de Borba; Isilda Guimarães (2014). Dinâmica de grupo como estratégia do processo de autoconhecimento em crianças do 3 ano do ensino fundamental I. Disponível em: <http://famesp.com.br/novosite/ wp-content/uploads/2014/tcc/famesp_lidiane_costa_lessa.pdf>. Acesso em 26 set. 2017.

Lово, Mercedes Leonor Illera (2017) «Relación de la teoría y la práctica en la enseñanza del derecho». Revista Espacios 38 (45): 1-5.

Martínez, Sérgio Rodrigo (2005). «Reflexões sobre o ensino jurídico: aplicação da obra de Paulo Freire aos cursos de Direito». Jus Navigandi, Teresina,9 (654).

Ministério DA EducaÇão (2004). Conselho Nacional de Educação. Brasil. Câmara de Educação Superior. Resolução CNE/CES nº 9, de 29 de setembro de 2004. Institui as Diretrizes Curriculares Nacionais do Curso de Graduação em Direito e dá outras providências. Brasília, DF, 2004.

Montoya, Juny (2010). «The Current State of Legal Education Reform in Latin America: A Critical Appraisal.» Journal of Legal Education 59 (4): 545-66.

Palazón-Pérez, Alfonso; María. Gómez-Gallego; Juan Cándido Gómez-Gallego, María Concepción Pérez-Cárceles, and Juan Gómez-García (2011).»Relación entre la aplicación de metodologías docentes activas y el aprendizaje del estudiante universitario.» Bordón. Revista de pedagogía 63(2): 27-40

Palomino, María del Carmen Pegalajar (2016). «Percepciones del alumnado de posgrado acerca de la metodología docente y evaluativa.» Profesorado. Revista de Currículum y Formación de Profesorado 20.2 (2016): 98-119.

Pinilla-Rodríguez, Diego; Héctor Rafael Reinoso-Vásquez; and María Eugenia López-Merino (2017). "Complexity, Legal Formation and Social Transformation. Some Notes.» Revista Jurídicas 14 (1): 87-101.

Prado-Carrera, Gina Jacqueline (2016). «Morality and Ethics: The Cornerstone in the Teaching of Law.» Opcion 32, Special Issue (13): 369-390.

Perpétuo, Susan Chio de; Ana Maria Gonçalvez (2005). Dinâmicas de grupos na formação de lideranças. Rio de Janeiro: DP\&A.

Pérez Perdomo, Rogelio (2018). «From Harvard to Stanford. On the History of the Legal Education of United States.» Boletin Mexicano de Derecho Comparado 50 (151): 313-358.

Rodríguez, Arturo; Ramírez, Leonardo and Washington Fernández (2017). «Active Methodologies to Achieve Comprehension.» Formación Universitaria 10 (1): 79-88.

Rui Tinoco, Débora; Cláudio Nuno Pereira de Sousa Junho (2014). Dinâmicas de grupo: boas práticas. PASSE 
Scheibel, Márcia Regina; Rosemari Silveira, Foggiatto Monteiro Castilho (s/f). Outro olhar para as técnicas de dinâmicas de grupo: as reais possibilidades educativas desta metodologia nos cursos de formação de professores. II Simpósio Nacional de Ensino de Ciência e Tecnologia, artigo número 125, Universidade Tecnológica Federal do Paraná, Programa de Pós-Graduação em Ensino de Ciência e Tecnologia.

Silva, Jorge Antonio Peixoto da (2008). «O uso de dinâmicas de grupo em sala da aula: um instrumento de aprendizagem experimental esquecido ou ainda incompreendido?» Revista Saber Jurídico, Porto Velho, 1 (2): 82-99.

Universidade Luterana do Brasil, Disciplina de Recreação e Lazer, https:// pt.slideshare.net/diogofcbarros/atividades-de-quebra-gelo.

WANDERLey, Alexandra e Ghelmann, Ana (2016). Dinâmica de grupo nas organizações: aplicação e técnicas.

WeIl, Pierre (1967). Dinâmica de Grupo e Desenvolvimento em Relações Humanas, Belo Horizonte: Editora Itatiaia.

WeIL, Pierre (1997). Organizações e tecnologias para o terceiro milênio: a nova cultura organizacional holística, Rio de Janeiro: Editora Rosa dos Ventos.

Zárate-Rueda, Ruth., Sonia Patricia Diaz-Orozco, and Leonardo Ortiz-Guzmán (2017). «Inclusive Higher Education: A Challenge for Pedagogical Practices.»Revista Electrónica Educare 21(3):289-312.

\section{Sobre os autores}

Natalia M. M. Prigol é Bacharel em Direito pela Faculdade de Direito Curitiba (2015). Advogada. Membro da J. Reuben Clark Law Society. Mestre em Direito pela Pontifícia Universidade Católica do Paraná (2016-2018). Doutoranda em Direito pela Pontifícia Universidade Católica do Paraná. Graduada em inglês jurídico pela Cambridge Law Studio (2013). Contato: nataliaprigol@hotmail.com.

Thiago Werner Ramasco é Graduado em Direito pela Faculdade de Direito Unicuritiba (2006). Especialista em Direito Administrativo Aplicado pelo Instituto Romeu Felipe Bacellar (2008). Advogado. Mestre em Direito pela Pontifícia Universidade Católica do Paraná - PUCPR. Contato: thiago.ramasco@gmail.com. 
